\title{
Insulation historical buildings from the inside
}

\author{
Krzysztof Janus \\ https://orcid.org/0000-0002-5391-3140 \\ k.janus@pollub.pl
}

Department of Architecture, Urban and Spatial Planning,

Faculty of Civil Engineering and Architecture, Lublin University of Technology

\begin{abstract}
This article focuses on the problem of thermal insulation of historical buildings. This issue is very important, especially for historical buildings and those not covered by any form of preservation maintenance. In the case of thermal insulation of this type of buildings, we often have to deal with irretrievable loss of architectural values and even with stripping the buildings from their history and identity and often turning them into architectural monstrosity. The article refers to both aesthetic, legal and technical issues, which should be kept in mind before planning thermal modernisation. It indicates the most common technical and system errors and points to certain changes that can minimise the problem of uncontrolled styrofoam covering of historical buildings.
\end{abstract}

Keywords: historical buildings, insulation historical buildings from the inside

\section{Introduction}

With the growing problem of global warming, ever-increasing amounts of carbon dioxide and smog and their detrimental effects, one of the ways to reduce the environmental impact is to perform thermal modernisation of buildings. The comprehensive thermal modernisation process not only contributes to the reduction of carbon dioxide or harmful substances emission to the atmosphere and the amount of fuel used, but also improves thermal comfort and conditions of use as well as reduces maintenance costs of buildings. In the case of new buildings, the insulation layer is already included in the project and in the case of existing buildings, as particular as old or historical buildings, the process is complicated, expensive, but possible to implement. One of the key factors (which is often forgotten by investors) is respect of the history of the building and its appearance. Often after insulation, the aesthetics of the building leaves much to be desired and its appearance makes it eligible for the "Makabryła" prize (awarded to the worst Poland's new buildings according to internauts), and the process of thermal modernisation can be described as a "thermal rape" on the history of the building.

The current technical possibilities and housing standards are the reason why the financial benefits of insulating buildings tend to overshadow the values of retaining their original architectural features or character. If historical buildings are not subject to preservation maintenance, then the decision on their look is only the responsibility of their owner, who chooses the most advantageous option, i.e. minimum costs, without taking into account the appearance of the building or the history it entails'.

This issue has been raised for years and yet, it has not been properly addressed by the legislator. The photographs below show the method of insulation of only a few buildings in the area of one street, one city, made in the last few years. Of course, they are not as "colourful" as many other examples, but they do represent an important aspect. 


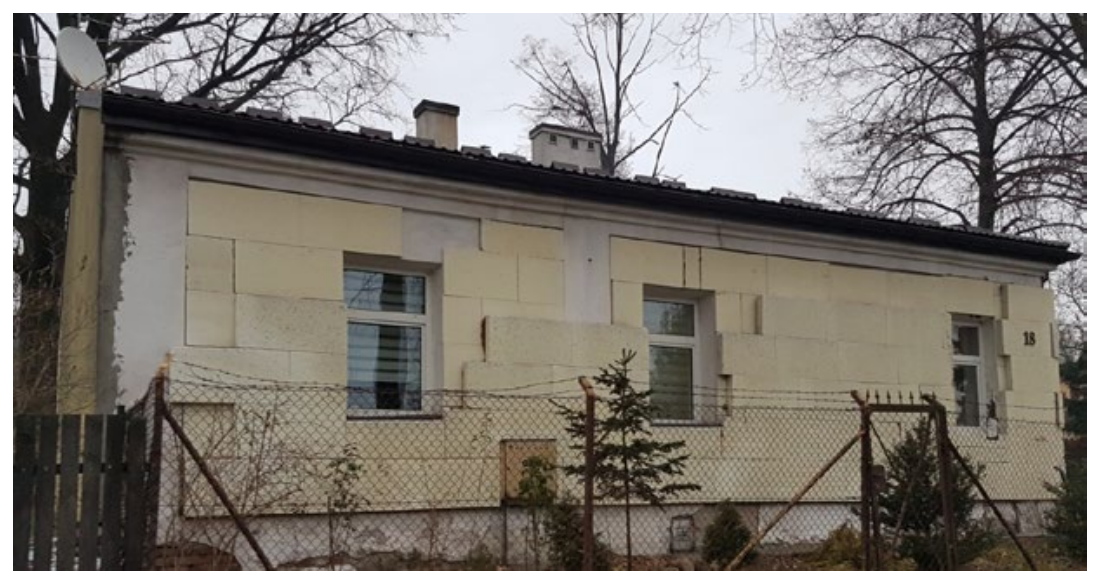

Fig. 1. An attempt to insulate the building from the outside, photo. K. Janus

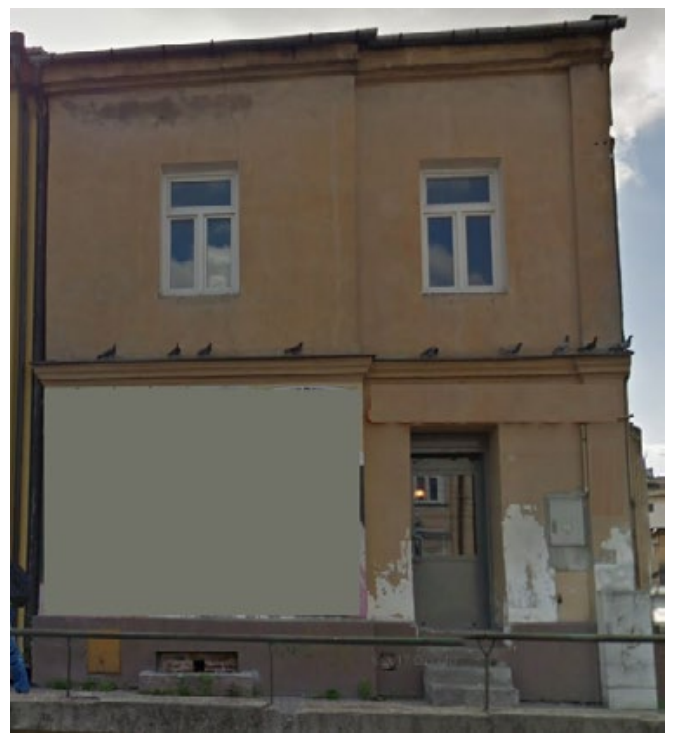

Fig. 2. Tenement house 1, www.google.com/maps/ street View, state of 2011, access: 15.08.2019

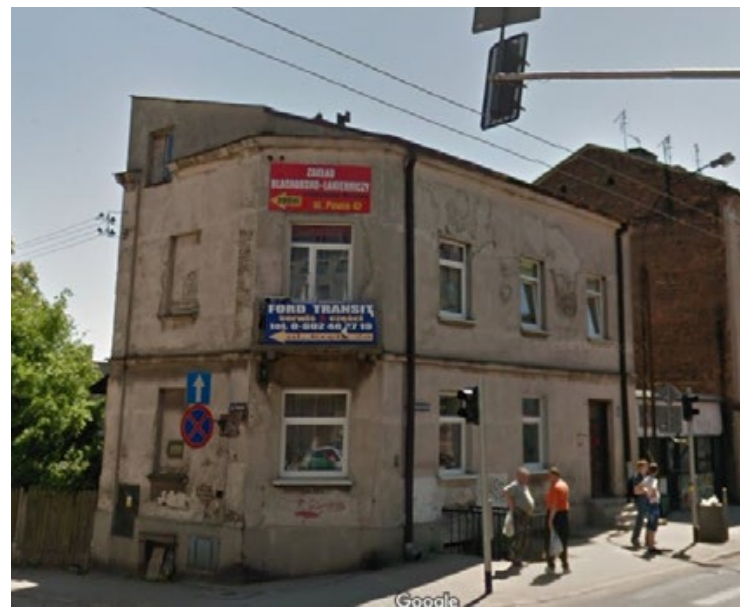

Fig. 4. Tenement house 2, www.google.com/maps/ street View, state of 2011, access: 15.08.2019

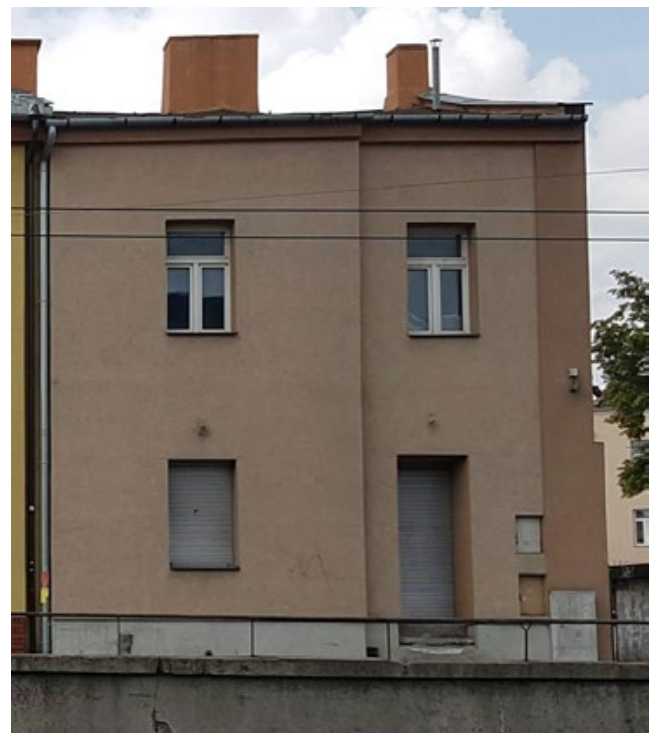

Fig. 3. Tenement house 1 , current state, photo $K$. Janus

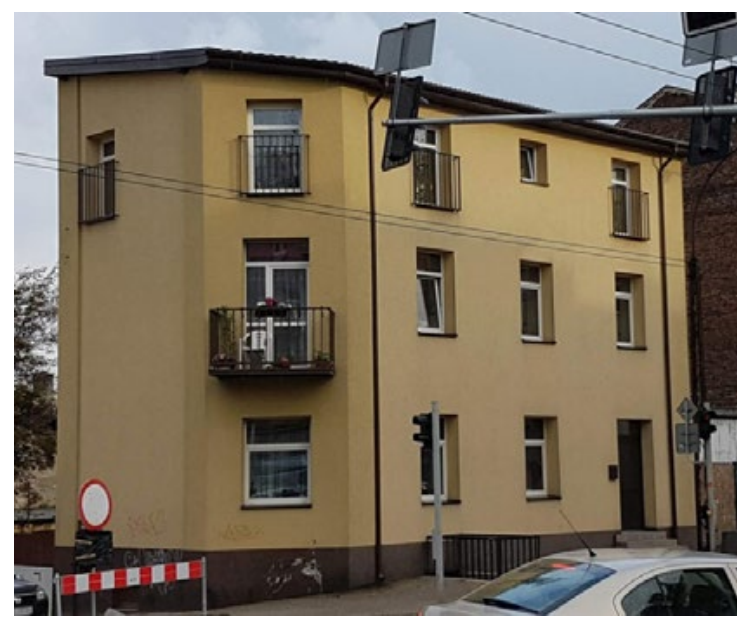

Fig. 5. Tenement house 2 with upward extension, current state, photo $\mathrm{K}$. Janus 


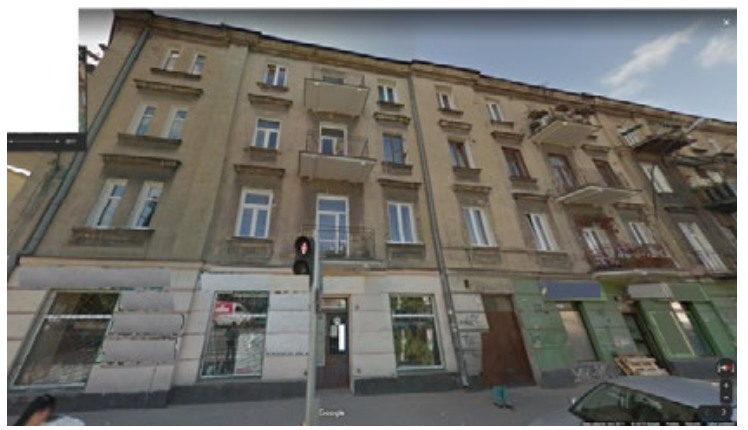

Fig. 6. Tenement house 3, www.google.com/maps/ street View, state of 2011, access: 15.08.2019

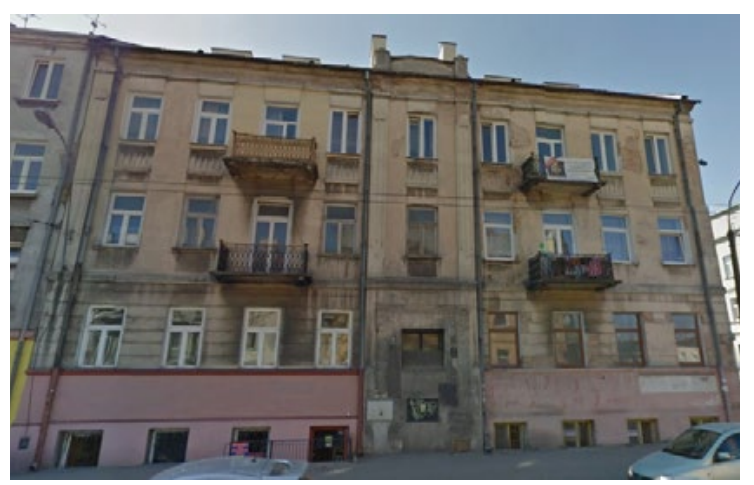

Fig. 8. Tenement house 2, www.google.com/maps/ street View, state of 2011, access: 15.08.2019

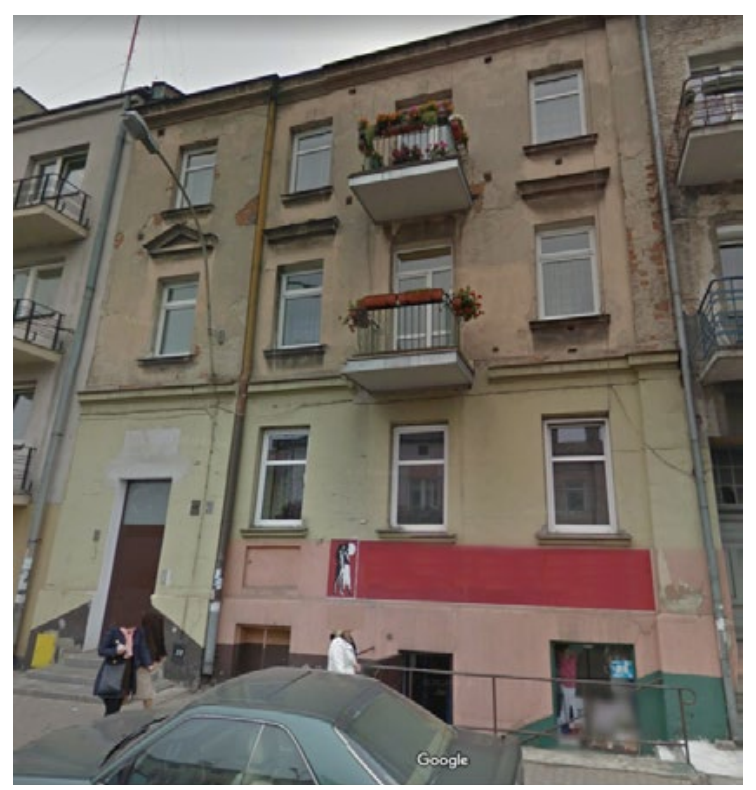

Fig. 10. Tenement house 4, www.google.com/maps/ street View, state of 2011, access: 15.08.2019

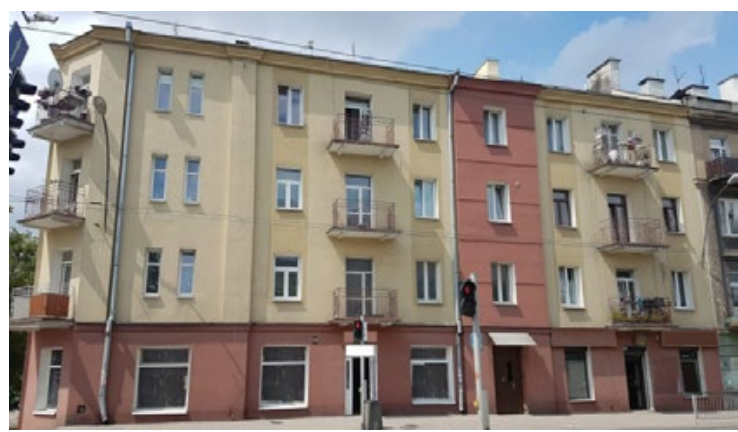

Fig. 7. Tenement house 3 with upward extension, current state, photo K. Janus

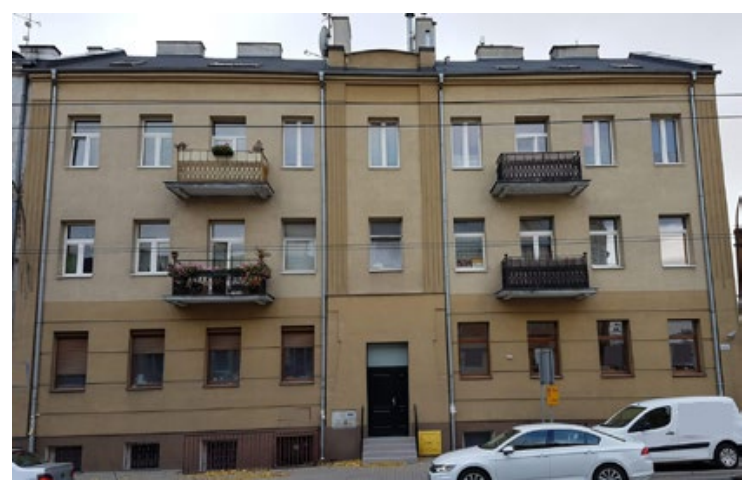

Fig. 9. Tenement house 2 with upward extension, current state, photo K. Janus

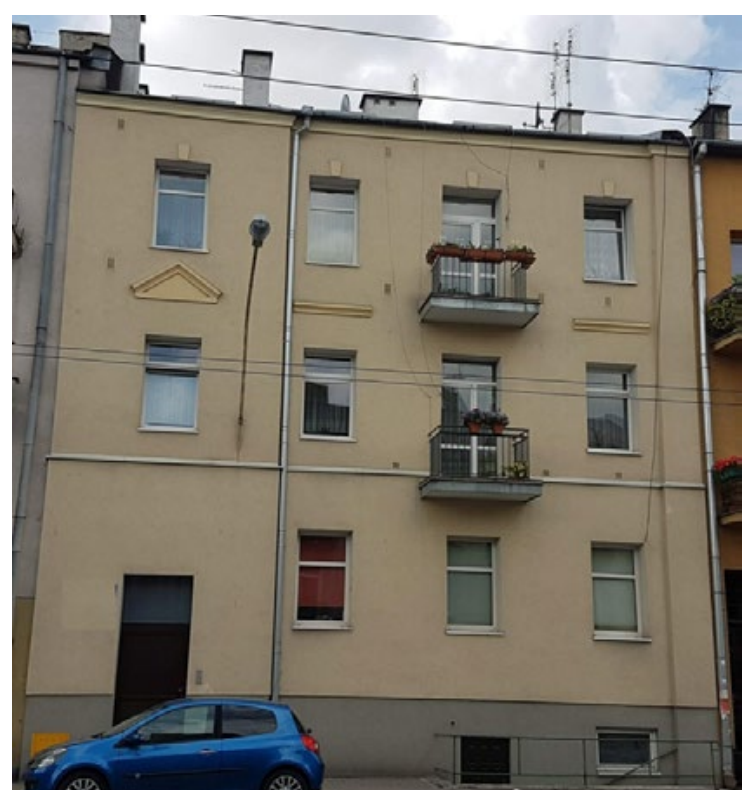

Fig. 11. Tenement house 4 with upward extension, current state, photo K. Janus 


\section{Applicable law}

\section{Construction law}

It is a basic reference document for both a designer and a contractor. On the basis of the regulations one can distinguish three categories of buildings provided by the legislator in terms of providing thermal insulation ${ }^{2}$ :

- buildings up to $12 \mathrm{~m}$ do not require a building permit or a notification,

- buildings of $12-25 \mathrm{~m}$ require a notification,

a buildings of more than $25 \mathrm{~m}$ require a building permit.

If the structures are covered by any form of preservation maintenance, then a conservation permit ${ }^{3}$, is required and the issuance of such automatically requires a building permit.

\section{Property rights}

This applies mainly to densely built-up areas (which is very common in the case of historical buildings). Adding an insulation layer may cause the takeover of a part of the adjacent plot, for which it is necessary to obtain the owner's permission, make changes in the land and mortgage registers, etc. ${ }^{4}$

\section{Copyrights}

The issue of copyrights in the construction industry is a complicated subject already in the case of new buildings, when a designer of a building and an owner of copyrights are known. In the case of historical buildings, which often exceed several dozen years of age, if their designer can be identified, the matter becomes even more complicated.

The copyright laws are quite clear. However, their interpretation and application in the administrative process for issuing permits is ambiguous. The decision to take this right into account depends on the administration or the individual opinion of the official and is applied only occasionally. This happens in the case of changes at the design or construction stage (prior to the acceptance of the building). After the completion of the construction process and the acceptance of the building, the application of this law does not actually occur in the administrative process. In some administrative bodies, however, it happens that the author or his heirs have to obtain permission to change the size of a window opening or to transform a blank into a window in buildings erected a few or several decades ago. It is not clear what are the reasons and criteria on the basis of which this law is applied or not.

\section{Technical issues and design}

Historical buildings, depending on the time of construction, were made of different materials, and with different technologies available at that time, but which were significantly different from those currently in use. The biggest difference in almost every case is the lack of waterproofing of foundations, thermal insulation or ventilation. The buildings were most often made of stone or limestone bricks. Both of these materials are very absorbent and easily absorb moisture (whether as a result of capillary rise of water, precipitation or dew point). This effect is more or less noticeable depending on many factors. It manifests itself in the form of moisture, 
mould and fungi, scaling and damage to plaster and masonry elements. They have a negative impact on the human body and can contribute to the development and formation of many ailments and even serious and chronic diseases. The degree of inconvenience or harmfulness to human health depends on many factors, starting from the location of the building, the type of land in which it was built, the type of ventilation, the method of heating, or the way of use $\mathrm{s}^{5}$. In order to minimise or completely remove these effects, it is necessary to take a multidimensional approach, including both design activities and the use of appropriate materials. The biggest problem is the proper selection of currently available technology fora building that was created several dozen or several hundred years ago.

The process of thermal modernisation of the historical buildings is a complex process and must involve a number of different activities. Very often it happens that in case of buildings up to $12 \mathrm{~m} \mathrm{high}^{6}$, the only person deciding on the method of thermal modernisation of a building is its owner after consulting a contractor, who does not even try to predict the consequences that it may have. Proper operation should be preceded by a thorough recognition of the technical condition of the building by a designer and the selection of the appropriate system, operation and material solutions, taking into account the requirements that the building should meet, both in terms of use and the applicable regulations. This process should be considered on many levels and take into account every aspect related not only to thermal modernisation but also to the areas it may affect.

\section{Foundations}

In case of lack of waterproofing, it is necessary to introduce an effective cut-off from moisture access. ${ }^{7}$ The most effective way is to dig out the foundations and insulate them, which is a relatively complex and expensive process $^{8}$. Other methods are also available, without the need to expose the foundations, such as injections.

\section{Ventilation, woodwork, heating}

Historical buildings most often did not have a ventilation system in its current form (supply and exhaust ventilation ducts). Air exchange took place through leaks in carpentry, ventilation ducts were sporadic, and the only available ones were smoke chimneys. In such a case, a new ventilation system should be introduced (particularly efficient in ground and basement rooms), depending on the needs and capabilities of the user, based on effective gravitational or mechanical ventilation or recuperation.

In most cases, the woodwork of historical objects was made of wood in a system adequate to the period of its construction. Glazing on fillers and twisting of wood was the cause of large heat losses but on the other hand, it allowed for ventilation. Nowadays, when replacing the window carpentry, one should remember to reproduce its layout and material ${ }^{9}$. The use of woodwork currently available on the market (wooden or plastic) ${ }^{10}$ results in the sealing of rooms, which without the introduction of additional ventilation, can lead to condensation of water vapour and consequently development of biological corrosion ${ }^{11}$. The minimum requirement is to introduce vent pipes on the windows.

After insulation, the heat demand is automatically reduced. Therefore, it should be taken into account that the heating system will require less heat energy. An absolute minimum is the modernization of thermostatic

5 Sometimes it happened that the soil in the foundation trench was exchanged for clay, which significantly reduced the perceptible moisture in the building. Other case was that foundation walls were made in a layered form - a void inside, which allowed to reduce the perceptible moisture or improve thermal conditions, but these were single applications in the case of very wet soils.

6 And these are the most common.

7 It is important to bear in mind that the execution of waterproofing in itself leads to the drying of walls, without the use of other methods such as microwave drying; after the complete elimination of capillary rise, the walls, depending on the thickness, level of moisture, etc. may dry for up to 10 years.

8 For this type of work, however, it is possible to insulate the foundation walls.

9 This is something that investors often do not remember when installing new windows without divisions.

10 Even in the case of woodwork, the wooden elements are soaked or impregnated to such an extent that they are almost as tight as plastic.

11 This is most often the case with window glyphs. 
valves in the radiators so that the excess heat is not extracted by the residents through an open window but with a valve.

\section{Thermal isolation}

There are hardly any thermal insulations in historical sites in modern understanding of the term. The wooden buildings used to have "zagaty" or "ogaty". It was an additional layer of insulation adjoining the façade, for which organic materials (moss, moss, wood, etc.) were used. With a thickness of up to one metre, this layer could significantly improve the insulation properties of a buildings. The thatched roof also performed very well in this respect. These solutions worked well for small wooden buildings. In the case of brick buildings, no external insulation was used, and large and high rooms were hard to heat, so they remained cold. The only solution to this problem was warmer clothing, beds equipped with a canopy that allowed them to "capture " a certain amount of heat to "survive" the night. The form of internal insulation was also provided by paintings and tapestries on the walls, which improved thermal comfort in a minimal but noticeable way. Buildings constructed several dozen or hundreds of years ago were not supposed to meet today's norms and standards, nor were supposed to use less energy in the future. Therefore, their thermal modernisation presents a great problem with the proper selection of technology adequate to the building, which will improve the thermal comfort of the users, meet current regulations and do not result in the degradation of the building.

The least problematic way of insulating external walls is to make an insulation layer from the outside. It is the most common method, relatively simple in execution and the cheapest. However, in the case of monument buildings it is used only occasionally. In the case of historical buildings, which are not under the preservation maintenance and their architectural values are sufficiently evident that it is impossible to provide insulation from the outside, the insulation is performed from the inside. Until recently, the only material that could be used for this purpose unobstructed was mineral wool. This material, although partially "breathing", is still not as perfect as it should be. Although it contributed to the formation of biological corrosion much slower than e.g. styrofoam, it still made it happen. For several years there have been products available on the market which are intended for insulating historical buildings, new products and complete solutions which enable such actions.

In terms of thermal insulation possibilities, the historical buildings can be divided into three categories:

- can be insulated from the outside (there are no architectural elements on the façade),

- can be insulated only from the inside (rich façade design),

- cannot be insulated from inside and outside.

In the case of buildings that can be insulated from the outside, it is important to choose the right technology for the technical condition of the building (take into account the damp walls), predict what consequences will arise from adding a layer of insulation, or how the insulating material will "age"12.

An interesting combination of the technology of insulating from the outside is the following example of a tenement house, where the insulation technology was applied on the outside of the building with a façade decor (modest but visible). The work included filling the space between the cornices with a layer of insulation, which partially covered the cornices, but did not significantly change the appearance and perception of the building. On the surface, windowsills were made as new elements. The façade finally obtained the "woodworm" texture, which could have been avoided, and the final finishing layer should have been the paint on the adhesive layer. In this case it was not possible to prevent thermal bridges, which (surprisingly!) are not very visible in the thermal vision or felt by the inhabitants. 

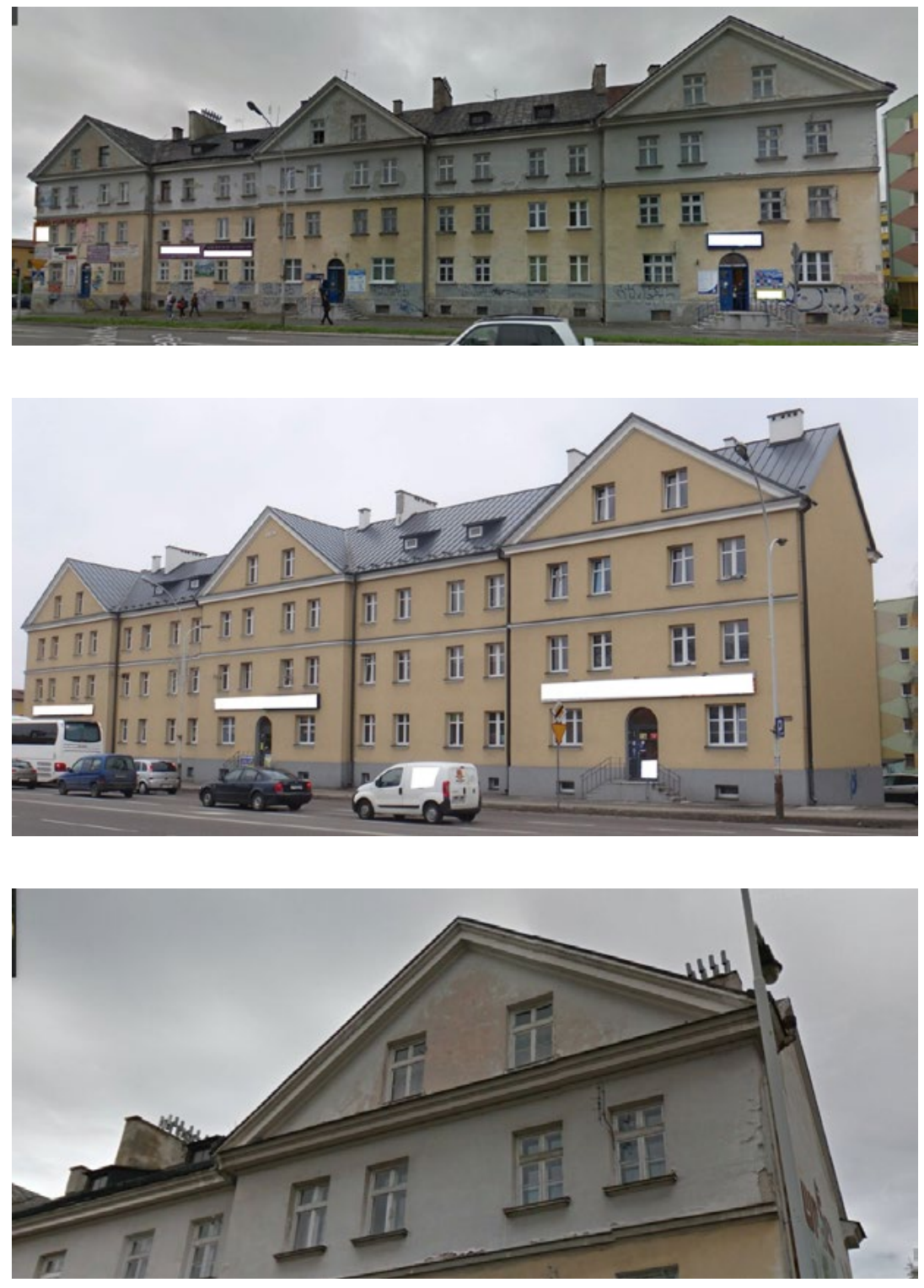

Fig. 14. Tenement house 4 , www google.com/maps/ street View, state of 2011, access: 15.08.2019

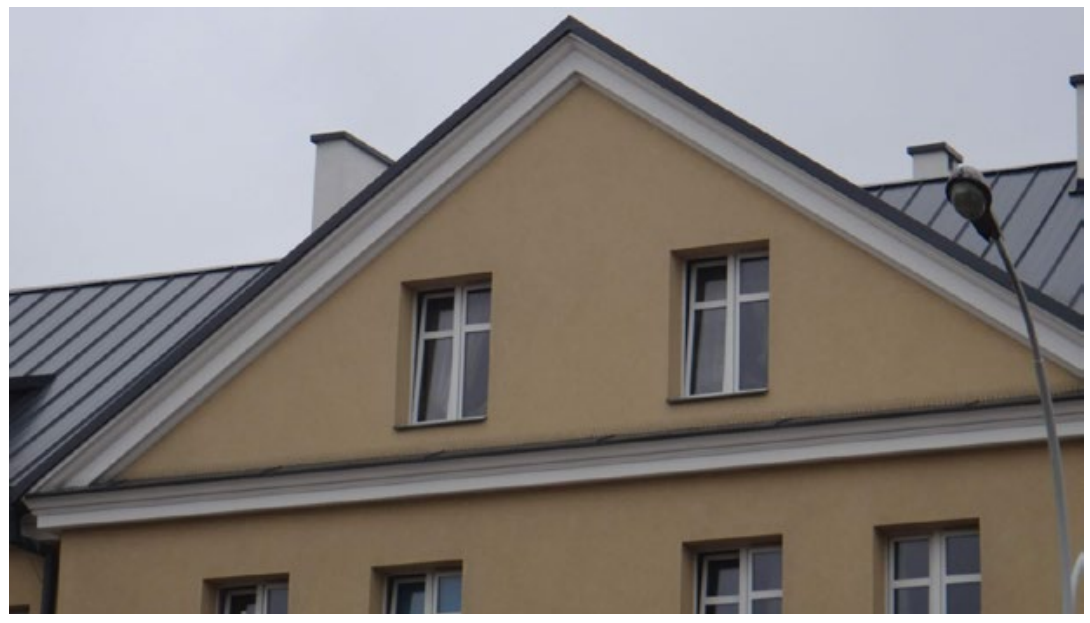

Fig. 12. Tenement house $6, w w w$ google.com/maps/ street View, state of 2011, access: 15.08.2019

Fig. 13. Tenement house 6 with upward extension, current state, photo K. Janus
Fig. 15. Photo 8 . Tenement house 6 with upward extension, current state, photo K. Janus 
For the second group of buildings, i.e. those that can be insulated from the inside, the problem of the dew point and water condensation in the wall in unfavourable temperature conditions has not been solved (this is the biggest disadvantage of this method, which still takes place in the current state of building). It is also problematic to insulate key places such as the connection of internal partition walls or ceilings with external walls. It is possible of course to add an additional insulation layer reaching deep into the room (visible in the form of a bump on the wall or ceiling), which in part would solve the problem, but in terms of aesthetics and conservation, e.g. in palace interiors, is simply unacceptable. It is also possible to consider insulation of all walls and ceilings from the inside, which would reduce the usable area and increase costs. Window glyphs, which due to the size of the window can be insulated with a thin layer of insulation (thinner than in the case of external walls), are a crucial point. Available technologies for internal insulation enable moisture flow from the walls to the interior and its removal through the ventilation system to the exterior, and properly selected $\mathrm{pH}$ of materials significantly reduces the risk of development of biological corrosion at the contact of the wall with the insulation layer. The biggest problem is the place where external walls are connected with the ceiling and internal division walls, where thermal bridges occur. This problem remains unresolved and its elimination may consist in limiting the effects, i.e. introducing efficient ventilation and the use of suitable materials that will reduce the risk of biological corrosion.

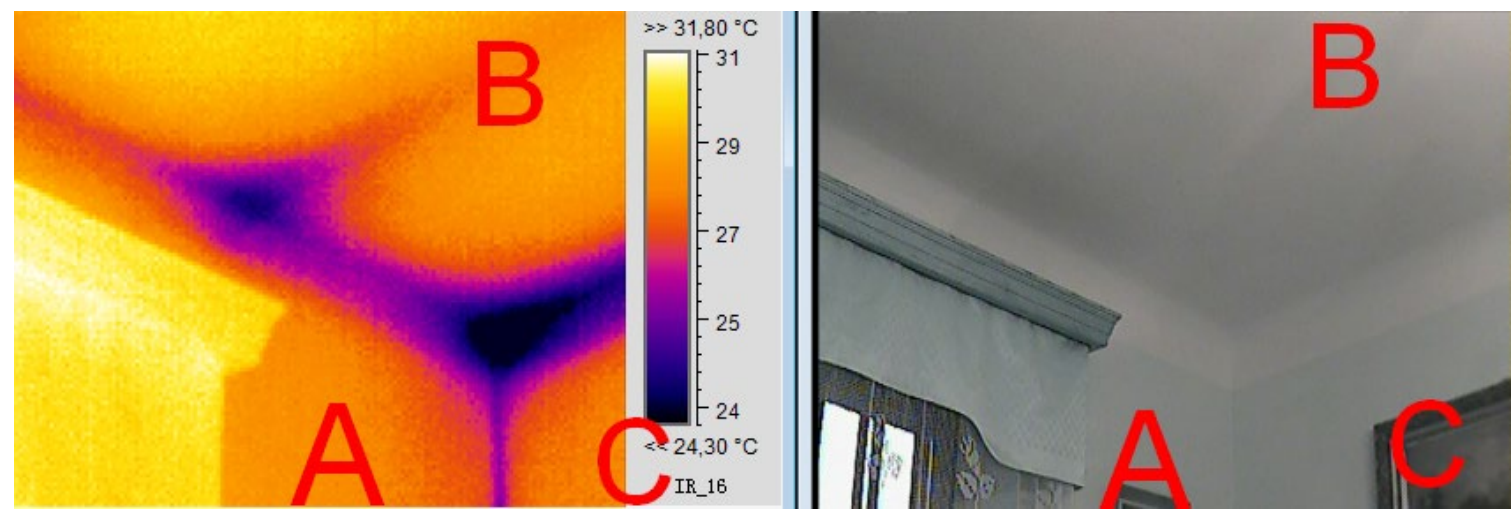

Fig. 16. Place of joint wall with insulation from inside with ceiling and internal division (A - wall insulated from inside, $B-$ ceiling without insulation , C - internal wall without insulation), K. Janus

After the completion of the insulation works, the facility should be monitored, which is something that investors or designers tend to forget. Small errors at the execution stage may be repaired or eliminated during exploitation of the facility, but without supervision it is impossible.

Already during the design process, it should be remembered that the walls insulated from the inside are "difficult to use". There is no problem with hanging a picture on a nail ${ }^{13}$, but the installation of larger elements (even a small cabinet) requires complicated actions and the use of special handles (the use of a standard dowel does not solve the problem, and in addition, a thermal bridge is created this way). A similar situation occurs in the case of electrical points (special boxes are available). It is necessary to be immediately prepared for the fact of limiting both electrical points and hanging elements on insulated walls.

If the foundation walls are insulated, they should be insulated from the outside with available materials, ${ }^{14}$ otherwise they should be insulated from the inside or completely abandoned, depending on the technical condition of the basement, the dampness level, etc. 


\section{Available materials}

For some years now, there have been products available that enable insulation from inside of buildings that significantly reduce the effect of condensation, mould formation, etc. The basic assumption is that it is necessary that this type of insulation "breathes", which allows moisture to pass through the building. As it turns out, these materials do better in this respect than wool, which most often laid from the inside, after a few years, moulds in the place of connection with the wall or floor. Each of these systems differs slightly from the others in terms of purpose, properties and application possibilities. It is not possible to unequivocally determine which of the presented solutions is better and which is worse. The optimal choice should be made on the basis of the technical condition of the building, the dampness of the walls, the way of use, location, floor, etc. Although the selection of systems for insulation even on specific floors is quite complicated, it is possible to insulate the building without changing the arrangement of the external façade, as well as to significantly reduce corrosion or mould.

In terms of technology, materials for interior insulation can be divided into two main categories:

Breathable materials (which should be used in most areas of the building, especially in areas where excessive moisture may occur).

Non-breathable materials (to be used only where this moisture is not present and, if present, must be able to evaporate freely).

Appropriate systems should be carefully selected, taking into account many factors, from the use of the rooms to their location, ventilation and exposure to sunlight.

All systems (except from the last one in Table 1) are based on sticking the insulation block to the wall with the use of an insulation adhesive. For this product, the insulation material is attached to the wall on a wooden grid. Its advantage is a low $\lambda$ coefficient, which allows the thickness of the insulation layer to be reduced to $8 \mathrm{~cm}$, but the material is sealed.

\section{Summary}

The far-reaching thermal modernisation of historical buildings under current trends is transforming into an uncontrollable process of progressive destruction of an important historical substance, most often dating back to the period before the First World War. Without further action, this process will continue and unfortunately the heritage of residential architecture (not spectacular enough to be entered into the register of monuments) will be destroyed or completely lose its character. It is not possible to convince the majority of users and owners that it is worth preserving even a simple façade decoration, keeping the building in its original colours, and that maintaining the arrangement of windows with their original divisions is important. The most relevant issue is cost reduction, which does not necessarily go along with respect for history. The latter occurs in few cases.

Thermal insulation of historical buildings from the inside using currently available technologies, allows to improve the energy efficiency of the building while maintaining the aesthetic values of the façade and the history of the building. These systems allow the walls to "breathe" and significantly reduce biological corrosion. The method, although it has many disadvantages (dew point, price, reduced surface area or limited actions on the insulated wall), makes it possible to perform insulation. This contributes to the reduction of nuisance to the environment, reduction of operating costs, and most importantly, it allows to preserve the historical appearance of the building.

The existing regulations allow for any action in historical buildings up to a height of $12 \mathrm{~m}$, which in practice means that three-storey buildings, which are the most common are the most threatened. While the technology of interior thermal insulation is easily accessible, the existing law and regulations do not prevent the ramping process of thermal insulation, which often turns into a form of "thermal rape".

If the regulation, allowing for insulation of buildings up to $12 \mathrm{~m}$ without the need to obtain a permit or notification, was extended by a time frame ${ }^{15}$ and a prohibition to change the look of the façade ${ }^{16}$, this process 
would be significantly reduced and many buildings could be "saved". However, the above would require statutory changes and such a regulation would transfer the entire responsibility for the insulation to the design$\mathrm{er}^{17}$, which would significantly reduce the "styrofoam cladding" of buildings and irreversible "stripping them of their historical identity"18. the Lublin departments responsible for issuing permits there is not a single one engineer available for the 18 employees).

18 In the case of thermal modernisation of a school at Kunickiego Street in Lublin, for failure to respect the historical layout, the LOIA Disciplinary Court suspended the designer's activity for a year and imposed a fine on him. 